\title{
Peculiar human resource management practices?
}

\author{
A case study of a microstate hotel
}

\author{
Godfrey Baldacchino
}

\begin{abstract}
This article explores the alleged pecularities of human resource management practices in very small developing states. A number of theoretical and ideo-typical features are culled from a literature review and are subsequently confronted with the empirical reality of human resource practices at Southern Bliss Hotel, a large, four-star tourist complex in Malta, the Mediterranean microstate. It is suggested that there are idiosyncracies to management issues in small size and small scale territories which call for recognition on their own terms. Some implications of these observations for hotel human resource management are explored.
\end{abstract}

A cursory glance at recent WTO statistics for Europe reveals that the highest contributions by tourism to GNP are enjoyed by Malta and Cyprus, the only two developing small island states in the region. ${ }^{1}$ This observation is more than sheer coincidence: contemporary evidence suggests that for many resource-poor developing countries, natural beauty and exotic culture may prove to be the only commercially viable assets in which they have a comparative advantage. This holds true particularly for the world's smallest states and territories. Thanks to sun, sea and sand, countries like Antigua and Barbuda, the Bahamas, Barbados, Fiji, the Maldives and Seychelles have developed a flourishing tourist industry which remains the largest contributor to direct and indirect employment, exceeding in significance any other economically productive activity. ${ }^{2}$ Insularity, smallness and isolation - otherwise a trinity of despair for industrialization -

The author is Visiting Lecturer, Labour \& Development Studies, Department of Public Policy and Research Officer, Workers' Participation Development Centre, both at the University of Malta, Msida MSD 06, Malta.

Submitted July 1992; accepted April 1993. foster instead the cultivation of a paradisiacal myth, an image of 'Eden without apples' which appeals to tourists from the cold, urbanized and repressed North. ${ }^{3}$

But is small size only a geographical parameter, a relevant detail only in so far as it conjures up an enticing image of warmth, exuberance, fantasy and romance? ${ }^{4}$ Could it be that smallness of territory serves also as a catalyst, generating somewhat idiosyncratic behaviour and, therefore, presents itself as a relevant analytic category? ${ }^{5}$

Several studies have, over the last three decades, juggled with this question, examining from the vantage point of this novel conceptual lens the viability of small developing states, their foreign policy, economic development, demographic constraints, financial management and, of late, environmental issues. These studies have dared to move beyond the position that small territories are faithful replicas on a miniature scale of larger countries; hence, that the theoretical framework which has been resorted to for the analysis of what obtains in larger jurisdictions can be applied just as validly to small ones. This challenging discourse has yet to be extended into the hitherto inadequately explored area of human resource management and labour policy.

If smallness and its consequences have implications for relationships between people, particularly between people at work, then human relations in the hotel industry would not constitute an exception. The focus is a happy one, since human resource management practices in a microstate hotel embody the dual legacy of smallness: its (distinct?) infection of labour relations; and its preconditional 'product image' contribution to the growth of tourism, on which the developing microstate's hotel industry 
depends. The latter is by now a hackneyed theme; the challenge is to illustrate the former and identify policy implications which ensue from the resort to this novel, conceptual framework.

The database for this exploratory article has been drawn from a case study of labour relations at Southern Bliss Hotel (henceforth SBH), a large, luxury, foreign-owned complex employing 210 fulltime staff operating in Malta, the Mediterranean microstate. Confidential, semi-structured interviews totalling 44 hours were carried out with 40 members of staff (18 management and 22 employee representatives) drawn randomly from all departments. The fieldwork was conducted by the author during the summer of 1991. The paper concludes with a critical discussion of these findings in the light of their implications for human resource management.

\section{Relevant features of the microstate syndrome}

From the literature on microstates, it is possible to abstract a number of key issues which are allegedly played out in a significantly diverse manner, in degree and/or kind, in most developing microstates.

\section{Vulnerability}

Microstates are prone to natural disasters, commodity price fluctuations and the whims of aid donors, foreign investors and tour operators. These are factors external to the microstate over which it has little, if any, influence. ${ }^{6}$ Such a susceptibility is exacerbated by the typically very slim range of products or services which the microstate has to offer to the international market, and the equally narrow range of customers for these same products. Hence such prosperity as may be achieved is a brittle and fragile one, ever at the mercy of changes of taste, technology, climate, demography and more efficient competition, not to mention military interests. When something disturbs this delicate equilibrium, the microstate economy can precipitate headlong, totally and rapidly, into crisis. ${ }^{8}$ In spite of the rhetoric of development plans and of planning in general, the question to ask is not if plans will go wrong, but when they will go wrong.

To mitigate the potentially harmful effects of such vulnerability, the response is often one of strategic diversification. This can take the form of multiple specialization of products and markets and the utilization of alternative, supportive production activities or sources of income. ${ }^{10}$ The power to relocate resources and to tap alternative options, thus hedging one's bets, is an important guarantor of survival, a 'security centred survival algorithm'. ${ }^{11}$ This often manifests itself at the individual level as occupational multiplicity or pluralism - the pursuit of several occupations, either simultaneously or successively. ${ }^{12}$ In spite of the prestige and social recognition afforded to specialisms, there is much to commend the multifunctional and polyvalent handyman orientation in microstates. ${ }^{13}$

\section{Intimacy}

The intensity of face-to-face interactions characteristics of many small-scale societies may be expected to become all the more acute in conditions of restricted space and high population density. Smallness thus fosters a sophisticated mode of accommodation, and this is enhanced by the complexity and durability of most social relationships. ${ }^{14}$ Because of the smallness of the total social field, many roles are played by relatively few individuals who are thus brought into contact over and over again in differing capacities. Impersonal standards of efficiency, performance and integrity are thus invariably cultivated. ${ }^{15}$ This interaction may accentuate cooperative relationships among some individuals and conflicting relationships among others. ${ }^{16}$ The actual pattern of interactions is mediated by socio-political, ethnic and/or economic realities which serve as anchoring cleavage functions, providing ideologies which legitimate in-group cooperation and out-group hostility in relation to the acquisition of scarce, prized resources.

The cultivation of networks and person-to-person coalitions is thus encouraged by the narrow social parameters. 'Friends of friends' can be constructed and manipulated selectively, serving as gatekeepers to improve access to desirables and therefore acting as mechanisms of interest satisfaction. ${ }^{17}$ Informal person-to-person recruitment is common within the labour market, not only because the scale of the enterprise or of the particular labour market segment tends to be small in absolute terms, but also because personal attributes - stressing allegiance, acquaintance and other ascribed criteria - may be seen to override merit and functional considerations in manpower selection. ${ }^{18}$

\section{Becoming expert}

In microstates there seems to be a relative ease in achieving a situation of self-professed and socially acknowledged expertise: Many plodders make it to the top. ${ }^{19}$ Such an authoritative standing is a function, inter alia, of (a) the flat social hierarchy: there are few intermediate rungs in the ladder of mobility, even though the competitors in the way may prove difficult to dislodge or overtake; various specialisms remain vacant and unrecognized until developed and proclaimed by enterprising individuals $;{ }^{20}$ (b) the fragility of the manpower system: with the manpower chain thinly stretched, a single break - through sickness, absence for training, or emigration - can cause disruption and considerable loss of efficiency; ${ }^{21}$ and (c) the discretion of job enlargement and job description lying in the hands of the individual, with superiors likely to be abroad or otherwise not actually supervising subordinates for 
significant stretches of time. These issues result in a potential for 'monument building'. ${ }^{22}$

\section{Interview material}

The case study undertaken at Southern Bliss Hotel serves to test some of these issues, singly and in combination, in a specific space-time environment. While doing so, it identifies new leads and directions towards a holistic understanding of the implications of smallness for labour policy. It also highlights the difficulty experienced by respondents in admitting practices and procedures considered as improper. if not outrightly corrupt.

Consider first the recruitment function. This is allegedly institutionalized at Southern Bliss: job applicants turn up regularly and their details are kept on file. Whenever a vacancy arises, it is initially advertised via an internal memorandum as stipulated in the extant collective agreement (the large majority of employees are unionized). If the vacancy remains unfilled after the procedure has run its course, then it is advertised externally, within the group which manages the hotel and in the local newspapers.

In practice, however, the story reads differently. External recruitment appears to depend by and large on an efficient grapevine of friends and relations which passes news of (among many other things) vacancies far and wide. Most employees recruited by SBH claimed that they owed their jobs to the informal employment agency which is the network of relatives and acquaintances, not to mention good contacts and anonymous patrons, in a position to pass on a good word or authoritative recommendation on one's behalf. Such networks appear to improve in quality and quantity as one gets older and accrues work and social experience:

The brother of one of the employees is my friend. He told me that there was a vacancy and that I could come to SBH to offer my services for the post. The employee whose brother was my friend then recommended me. (Gardener, male)

My cousin found out that I was looking for a job. He talked to someone else and I suddenly found myself being interviewed at SBH. (Telephone operator/receptionist, female).

I was unemployed. One of the supervisors at SBH was talking to my sister. She told her that I was looking for a job. The supervisor checked whether more staff was needed. I was then told to come and apply. I started within two days. (Chambermaid, female)

Managerial representatives are not exempted from resorting to such tactics even though they are under greater pressure to conform to officialdom and so to conceal or refuse to admit such practices. Interestingly, even trade union representatives are game to such behaviour. From the individual worker's viewpoint, the capital-labour, us-them traditional duality may fade into insignificant rhetoric: an immediate superordinate and a union steward or delegate are equal potential candidates for patronage and social brokerage.

Second, the 'jack of all trades' orientation, being a natural defence mechanism to the consequences of unpredictable erraticness in the open microeconomy, is evident in the occupational histories of the respondents, particularly those recruited to the relatively unskilled jobs in the hotel - cleaning, housekeeping, dishwashing, maintenance. From the 22 employees interviewed, only five had any experience of working in a hotel prior to joining SBH. Most had work experiences which were very different from the demands and character of the tourist industry. The variety of prior job profiles included a cross-section within manufacturing industry: cutters, machine operators, assemblers, supervisors, apprentices or watchmen. Many had found themselves redundant when their employer closed down or trimmed the work-force. The option to migrate was taken up by at least six of these worker respondents. Their working lives bore witness to shifting roles and shifting jobs, as the workers act on or react to sudden economic setbacks or opportunities.

No wonder that one foreign manager at SBH was suprised to find applicants who professed to be capable of a number of diverse tasks - the selective and strategic activation of multiple options is quite a natural response to occupational uncertainty:

The beginning was very hard. We started with a bunch where nobody knew anything. On their application, people wrote down that they could cook, wash, wait, clean. Whatever was needed, they were prepared to provide. (Executive chef, male)

Perhaps even more surprising is the impudence with which dilettantes proclaim expertise. There seem to be very few around, if any, to challenge one's authoritative pronouncements:

In Malta, you put one in a job and, presto, he's a cook. Next year, he's an expert. (Executive chef, male)

If someone could peel potatoes, he would pass as a cook. (Financial controller, male)

A totally different employment policy is played out with the more experienced or qualified employees. This observation applies mostly to the top and middle management levels as well as to cooks, chefs and certain front office personnel. Here a 'domino effect' apparently enters into play whereby individuals transfer their labour power by leapfrogging from one employer to another within the same industrial niche, according to the opportunities or necessities of the moment. The up-market hotel industry in Malta, as with other microstates, consists 
after all of a very small number of units: the opening or closure of any one of these causes ripple effects as specialist workers either choose or are obliged to switch employment.

Luring such prized and rare individuals can be executed by grasping the opportunities presented by market dynamics:

Grand Hotel Regis had to close down in 1982. Occupancy was low; there were problems with the trade union on lay-offs; the operators decided to pull out. Certain key members of staff found alternative employment at SBH: the Restaurant Manager, the Coffee Shop Manager, the Chief Engineer, the Head Storekeeper. . . . (Night manager, male)

Otherwise, a suitably tempting bait may be prepared. The small size of this specific labour segment improves the knowledgeability of people and of each other's skills, experience and price:

When construction work on the hotel was still going on, the General Manager was recruiting staff. He used to steal people from the Royal and Island Hotels, thanks to his previous connections. And when the White Sands Hotel opened in 1987, it stole workers from us. Our Executive Housekeeper left here to join White Sands. She was offered more money. (Catering manager, male)

If staff is not available, you poach. It would be stupid not to do so. (Purchasing manager/night relief manager, male)

Third, the hotel and catering industry is already fertile ground for personalized relations between manager and managed: various authors have documented how the need to respond quickly and effectively to demand necessitates a resort to flexibility. Workers generally concede this in return for some kind of compensation - petty theft, a convenient roster, overtime. Managers are generally amenable to this practice which they may themselves promote because it encourages the building of personalized loyalties which strengthen their authority, allow them a free hand in indulging in divide-andrule strategies and at the same time undermine collective worker solidarity and trade union consciousness. ${ }^{23}$

Within this scenario of often unconscious manoeuvres, disputes flare up sporadically when the unwritten tacit obligations of mutual appeasement are seen to be somehow being infringed and dishonoured. Such episodes appear to occur readily in the context of alleged discrimination, especially in the granting of leave, overtime, allowances and, above all, promotions.

In small societies, the combustibility of labour relations is idiosyncratic because of the intensification of personal encounters: intimacy and nepotism can harden relationships both ways. Not only sympathies but antipathies can become fused and difficult to dislodge. There are thus both networks and anti-networks at play, and these may prove to be either the tactical saving grace or the downfall of aspiring individual workers in the context of their dealings with superiors:

It happens in Malta. If you know someone high up and you want someone to find a job, it helps. We here in Malta suffer a lot from this. If you know the right person, you'll get a job without any problem. If the Personnel Manager gets to know that I have a son who wants a job here, even if he's not so capable, he'll get the job. (Gardener, male)

I had so many disputes. But I finished up as a loser because I didn't know anybody. There was no one I knew to whom I could go, inside or outside the hotel. (Chambermaid, female)

Smallness exerts an influence. Society is a total chain network. It's easy to blacklist an individual. And, conversely, it is just as important to have a patron. (Debt collector, male)

It's worse when people know each other. There can be abuses. If people are related or know each other, they can have more power. If you admonish someone s/he may feel insulted. The matter will be referred to his/her mate or relative and the case escalates. (Dishwasher, male)

\section{Managerial reactions}

The main trouble with the foregoing practices is that they are not readily discernible or acknowledged in microstate settings. Microstate citizens may know, often unconsciously, how to play ball ad nauseam with such 'common knowledge' in daily routine. But managerial representatives - especially of foreign nationality and/or having trained abroad - rely on expatriate blueprints of managerial functions and processes. The hallowed canons of textbook management are slavishly pursued.

There appear to be three general ideal types of reactions, of attempts at coping with the discrepancy between the theory and practice arising from such situations. The first is to refuse to acknowledge the microstate specifics other than as pathological manifestations, deviations to be rectified and weeded out of the hotel operation. In adamantly sticking to the official, proper script, management is perhaps anxious not to fall for the effects of country smallness because these could jeopardize its authority and control over the labour input and the ability to avoid conflict escalation:

Networking? This does not concern me as long as we have efficiency. One has to go through the procedure as laid out.

Friends of friends make no difference. ... News may travel fast but this has no influence on human relations.

Second, managers are prone to strive doggedly to fit the microstate practice into the standard doctrine. In 
the process, they may experience chronic exasperation:

According to international hotel practice, people related to each other should not work in the same hotel. But if we were to do that, then we wouldn't find enough staff. We try to enforce it but we don't succeed. (Assistant general manager, male)

Friendship is a form of blackmail. If the worst comes to the worst, it may prove difficult to fire a friend or relative. Too much familiarity breeds contempt. (Assistant accounts manager, male)

Third, there is also a realization that becoming sensitive to these dynamics is a crucial asset for effective human resource management in the microstate hotel. Is this expression not representative of the highest order of successful response?

There is increased pressure and tension to tread delicately and sensibly across the intense emotionally and personally charged loves and hates which bind individuals. You get to know that someone will definitely not speak to someone else. You find yourself involved. (Porter/telephone operator, male)

\section{Expressions of sensibility}

Let us take this issue further and explore how SBH management strive to become true masters of the game by exploiting and taking advantage of (rather than challenging or refusing to acknowledge) facets of the microstate experience. One of these concerns the nurturing of a feel for networks and antinetworks. Even though the best form of recruitment may be by word of mouth, there is all the same an awareness that this allows individuals to recruit networks into the enterprise, strengthening their manipulative advantage. ${ }^{24}$ One strategy here is to encourage network differentiation within an overall divide-and-rule strategy; the information grapevine which rides on network arrangements can also be readily utilized to obtain priceless news:

Familiarity is an advantage because you know more about the character of a new recruit. If you want to know something about someone, shop around for news. Soon, you'll know from $A$ to $Z$ about the person. (Chief security officer, male)

A second relevant example concerns how to manage the extensive networking which infiltrates all corners of the microstate social universe. In this way, no one is spared from scrutiny, either inside or outside the workplace. One must always be on guard and behave properly. Otherwise any slip, any impropriety will become common knowledge. This is a source of tactical power. Employees may use this as a blackmailing weapon, extracting concessions from otherwise reluctant managerial incumbents:
You have to watch what you're doing. If you err, you're done for, even professionally. I always try to keep straight and to be fair. . . . If someone finds a weakness in you, you may be blackmailed over it. (Financial controller, male)

The grapevine is extensive. Whether one likes it or not, some members of staff come from the same village, from the same street. If a manager has a drink with a guest and a member of staff gets to know, soon everyone is briefed. He's liable to blackmail. Say he tries to issue a warning. They'll phone his wife, scratch his car. . . . (Purchasing manager, male)

Yet another episode features the ease with which, in the tight labour market setting of the microstate, individuals can proclaim and command expertise in a particular skill or resource niche. This structural advantage generates a tendency towards monopoly labour supply, one which grants extra discretion and quasi-professional status to the producers involved. This almost inevitable trend can again be recognized and managed effectively by a tactical appreciation of the potential for increased corporate identity and enterprise commitment that such an expertise can generate. However, this 'human resource management' orientation will only deliver the goods if properly acknowledged and cultivated; the worker concerned must experience such a 'core' location in the enterprise. Unfortunately, management often dismisses these attempts as upstart presumptuousness which, in their ad hoc orientation, could even be mistakenly perceived as threats to traditional authority. Regrettably, the latter fear may be more likely to materialize when management seeks to cut the worker involved down to size. A shrewd 'indispensable' producer may take sweet revenge on a manager who refuses to grant the discretion, assertiveness and self-responsibility he/she feels are his or hers by right:

I clashed with my head of department. He issued a warning; I paid him back by taking a week of sick leave. He eventually tore up the warning. He had better keep his distance because he will be the one to suffer. I spent a week at home watching videos. (Electrical fitter, male)

There may yet prove to be more insightful examples to be drawn, outcomes of the features associated with facets of the microstate condition succinctly described earlier. They are not awaiting discovery: microstate citizens have long incorporated them into their survival kit. Rather, they beckon an acknowledgement and a formal assimilation into management techniques.

\section{Conclusion}

It is comfortable and comforting to think in stereotypes. And since people are easily seduced by grand cosmic explanations, to which they may have 
long been socialized, then it is no wonder that an incisive theory of smallness has yet to raise its head above the waters. When smallness is recognized, it generally manifests itself with an exotic quaintness, a Lilliputian slant which dismisses the small setting from any serious analysis. Yet even though the flotsam and jetsam of former empires may be easily left out of world maps, they stubbornly persist. Microstate citizens, above all others, have a responsibility to burst the doctrinal bubble and understand the physical and social ecology of their environment on its own terms.

Here, the obvious question to ask is: to what extent is the above behaviour really peculiar and exclusive to small states? Hotels are after all notorious for informality, staff are renowned for polyvalency and the practice of poaching of key personnel in the industry is widespread. Indeed, what is being described seems to occur in most physically isolated communities and localized labour markets. Possibly, a solid case may be made for microstatehood as intensifying the dynamics by tightening the operationalization of the variables of the social field even further: labour markets, space, resource and environmental management, networking, social monopolies, multiplier effects, communication systems, niche creation and preservation by individuals and groups. The argument does not suggest that smallness is a magical attribute with deterministic powers; it appears rather as a condition which provides a strong indication of, inter alia, a possible type of social environment which governs (and is in turn governed by) the lives of the producers concerned. What may thus be (or is purported to be) exceptional elsewhere may be more typical in small milieux. Indeed, such inductive microstate theorization seems to suggest important lessons at least for other small-scale communities the world over, such as isolated settlements and island territories. If this is the case, then the argument would have a much wider validity than the coy and petty microstate jurisdiction. A single case study is not the ideal research design to warrant such conclusions; but this is intended as a seminal paper, and what appears a limitation is meant to be a challenging proposal. Further research is called for here, particularly in other small size/small scale contexts, to validate or refute the 'smallness syndrome' sketchily illustrated in this paper, and to delve deeper into its theoretical and policy implications.

\section{Acknowledgement}

The article is based on the author's doctoral research into the labour policy and labour relations practices of small developing states at the University of Warwick, UK. Thanks to Robin Cohen, Peter Fairbrother, Peter C.W. Gutkind and Richard Hyman (at Warwick); Michael J. Boella (Brighton); Peter
Peculiar human resource management practices?: G Baldacchino

U.C. Dieke (Strathclyde); Janis Taylor (Marriott Corporation); Graham M.S. Dann (University of the West Indies); Joe Lanzon (Malta) and an anonymous referee for their insightful criticism on an earlier draft of this paper. The assistance of the Commonwealth Fund for Technical Cooperation and of the Universities of Malta, Warwick and the West Indies in supporting my fieldwork is gratefully acknowledged. Responsibility for the contents of this article remains, however, the author's alone.

Note also that all hotel names used in this article are fictitious, even though (and this is another inevitable consequence of smallness) it is not difficult for anyone who has been to Malta to identify the establishments in question.

\section{References}

'World Tourism Organisation, WTO Tourism Trends Worldwide and in Europe 1950-1990, World Tourism Organisation, Madrid, 1991, p 41. In accordance with the most popular (albeit invariably arbitrary) definition, small developing states or microstates are considered as being those former colonial territories with a resident and native population of less than one million. There are three dozen such territories in the world today, with three main clusters in the Caribbean, South Pacific and Indian Oceans.

${ }^{2} \mathrm{~B}$. Legarda, 'Small island economies', Finance and Development, Vol 21, 1984, pp 42-43; J. Connell, Sovereignty and Survival: Island Microstates in the Third World, Research Monograph No 3, Dept. of Geography, University of Sydney, Sydney, $1988, p 62$.

${ }^{3} \mathrm{D}$. Lowenthal, West Indian Societies, Oxford University Press, London, 1972, p 13; C.E. Diggines, 'The problem of small states', The Round Table, No 74, 1985, pp 191-205, esp p 192.

${ }^{4} \mathrm{R}$. Cohen, 'Introduction' in African Islands and Enclaves, Sage, London, 1983, pp 9-20, esp p 15; D. Pitt, 'Sociology, islands and boundaries', World Development, Vol 8, No 12, 1980, pp 10511059 , esp p 1051.

${ }^{5} \mathrm{G}$. Baldacchino, 'Bursting the bubble: the pseudo-development strategies of microstates', Development and Change, Vol 24, No 1. 1993, pp 29-51.

${ }^{6} \mathrm{~A} . J$. Dolman, 'Paradise Lost? The past performance and future prospects of small island developing countries', in E.C. Dommen and P.L. Hein, eds, States, Microstates and Islands, Croom Helm, London, 1985, pp 40-69, esp p 42.

${ }^{7}$ W.G. Demas, The Economics of Development in Small Countries with Special Reference to the Caribbean, Center for Developing Area Studies, McGill University Press, Montreal, 1965, pp 90-91.

${ }^{8}$ R.G. Ward, 'The consequences of smallness in Polynesia', in Burton Benedict, ed, Problems of Smaller Territories, Athlone Press, London, 1967, pp 81-96, esp pp 81-82.

'Demas, op cit, Ref 7, p 149; E.B. De Kadt, 'The issues addressed', in E.B. De Kadt, ed, Tourism; Passport to Development?, Oxford University Press, London, 1979, pp 3-76, esp p 22.

${ }^{10}$ H.C. Brookfield, 'Multum in Parvo: questions about diversity and diversification in small developing countries', in P. Selwyn, ed, Development Policy in Small Countries, Croom Helm, London, 1975, pp 54-76, esp p 71 .

${ }^{11} / \mathrm{bid}$, pp 56-57.

${ }^{12}$ R.E. Looney, 'Macroeconomic consequences of the size of Third World nations: with special reference to the Caribbean', World Development, Vol 17, No 1, 1989, pp 69-83, esp p 76.

${ }^{13} \mathrm{P}$. Bennell, and J. Oxenham, 'Skills and qualifications for small island states', Labour and Society, Vol 8, No 1, 1983, pp 13-38, esp p 24.

${ }^{14} \mathrm{M}$. Gluckman, Custom and Conflict in Africa, Blackwell, Oxford, 
Peculiar human resource management practices?: $G$ Baldacchino 1963, pp 18-19.

${ }^{15} \mathrm{~B}$. Benedict, 'Sociological aspects of smallness' in Benedict, op cit, Ref 8, pp 45-55, esp pp 48-49.

${ }^{16}$ R.T. May and S. Tupouniua, 'The politics of small island staies', in R.T. Shand, ed, The Island States of the Pacific and Indian Oceans: Anatomy of Development, Monograph No 23, Development Studies Centre, Australian National University, Canberra, 1980, pp 419-437, esp p 425.

${ }^{17} \mathrm{D}$. Pitt, 'Anthropological and sociological theories and microstates', in Dommen and Hein, op cit, Ref 6, pp 30-39, esp pp 31-32.

${ }^{8}$ Benedict, op cit, Ref 8, pp 48-49.

${ }^{19} \mathrm{M}$. Bray and H.E. Fergus, 'The implications of size for educational development in small countries: Montserrat, a Caribbean case study', Compare, Vol 16, No 1, 1986, pp 91-102, esp p 94; $\mathrm{J}$. Kersell, 'Government administration in a small microstate: developing the Cayman Islands', Public Administration and Development, Vol 7, No 1, 1987, pp 95-107, esp p 106.

${ }^{20} \mathrm{R}$. Boyce, 'Barbados', in M. Bray, ed, Ministries of Education in Small States: Case Studies of Organisation and Management, Commonwealth Secretariat, London, 1991, pp 106-122, esp
P 113; M.E. Peters and F. Sabaroche, 'Dominica, in ibid, pp 123-138, esp p 133; J. Rodhouse, 'Jersey', in ibid, pp 209227, esp p 219

${ }^{21}$ Bray, op cit, Ref 20, pp 57, 64-66.

${ }^{22} \mathrm{D}$. Murray, 'Microstates: public administration for the small and beautiful', Public administration and Development, Vol 1, No 4, 1981, pp 245-256, esp p 253.

23Y. Gabriel, Working Lives in Catering, Routledge and Kegan Paul, London, 1988; G. Mars, Cheats at Work: An Anthropology of Workplace Crime, Unwin Counterpoint, London, 1982; G. Mars and P. Mitchell, Room for Reform? A Case Study of Industrial Relations in the Hotel Industry, Unit 6, Industrial Relations Course P881, Open University Press, Milton Keynes, 1976; G. Mars and M. Nicod, 'Hidden rewards at work: the implications from a case study of British hotels', in S. Henry, ed, Can I have it in Cash? A Study of Informal Institutions and Unorthodox Ways of Doing Things, Astragal, London, 1981, pp 58-72; R.C. Wood, Working in Hotels and Catering, Routledge, London, 1992.

${ }^{24}$ M.J. Boella, Human Resource Management in the Hotel \& Catering Industry, 4th edn, Stanley Thornes, Cheltenham, 1988, pp 67, 140. 